\title{
Access Route for Endovascular Neurointervention - Transfemoral to Transradial: Is it Worth the Effort and are we Ready for the Change?
}

\author{
Chirag Kamal Ahuja ${ }^{1, \#(\mathbb{0}}$ \\ Vivek Agarwal ${ }^{2, \#}$ \\ ${ }^{1}$ Division of Neuroradiology, Department of Radiodiagnosis and \\ Imaging, Post Graduate Institute of Medical Education and Research \\ (PGIMER), Chandigarh, India \\ 2 Division of Neuro and Vascular Intervention, Department of \\ Neurology, Christian Medical College, Ludhiana, Punjab, India \\ ${ }^{3}$ Department of Interventional Neuroradiology, Paras Hospital, \\ Panchkula, Haryana, India
}

Sameer Vyas ${ }^{1}$

Vivek Gupta ${ }^{3}$

\author{
Address for correspondence Dr. Chirag Kamal Ahuja, DM, \\ Department of Radiodiagnosis and Imaging, Post Graduate Institute \\ of Medical Education and Research (PGIMER), Chandigarh 160012, \\ India (e-mail: chiragkahuja@gmail.com).
}

J Clin Interv Radiol ISVIR 2022;6:184-189.

\begin{abstract}
Keywords

- transradial

- endovascular

- neurointervention

- access route

Transfemoral access for neurointerventions has been a time-tested technique of entering the vascular network of the body and reaching the intended targets. However, it has its own share of shortcomings in the form of long admission times leading to increased costs, patient inconvenience and local (though infrequent) adverse affects. Transradial route has taken the interventional cardiology domain by storm and is staring now at other vascular domains especially neurointervention. It has shown better outcomes than the transfemoral route in many aspects. The current article discusses the vascular access perspectives with an exhaustive overview of the transradial route concerning its historical perspectives, its requirement in the current clinical scenario, the procedure per se including the adverse effects and whether it has the real world charm to displace the transfemoral route into the backseat. Transradial access in neurointervention is here to stay, however it would require training, certain modifications in the standard catheters that one currently uses for cerebral procedures and constant practice by the operator to cross the learning curve and attain a certain level of competence before he becomes comfortable with the technique.
\end{abstract}

\section{Access Routes: Historical Perspective}

Cerebral Digital subtraction angiography (DSA) is considered the gold standard for diagnosing intracranial vascular pa-

\footnotetext{
\# Chirag Kamal Ahuja and Vivek Agarwal contributed equally to the manuscript and are eligible for joint first authorship.
}

article published online November 11, 2021
DOI https://doi.org/ 10.1055/s-0041-1737026. ISSN 2457-0214. thologies. In addition to the structural information, it also provides excellent hemodynamic aspects of the lesion. Cerebral angiography procedure was initially described in 1920's by Professor Egaz Moniz who injected bromides and iodides directly into the carotid and vertebral vasculature. ${ }^{1}$ Since the advent of cerebral angiography, the trans-femoral arterial access (TFA) has remained the favorite approach route among

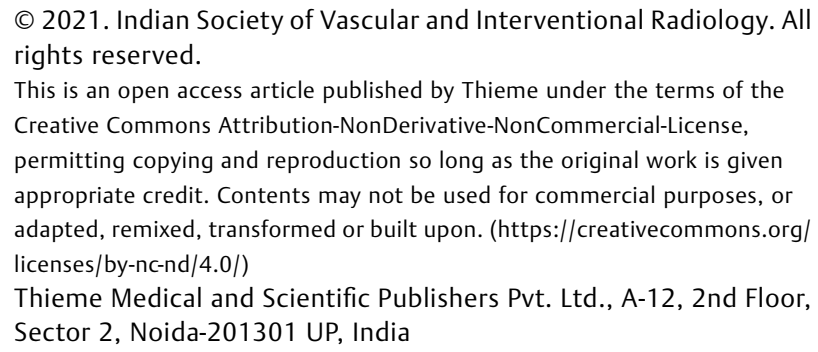

(c) 2021. Indian Society of Vascular and Interventional Radiology. All rights reserved.

This is an open access article published by Thieme under the terms of the Creative Commons Attribution-NonDerivative-NonCommercial-License, permitting copying and reproduction so long as the original work is given appropriate credit. Contents may not be used for commercial purposes, or adapted, remixed, transformed or built upon. (https://creativecommons.org/ licenses/by-nc-nd/4.0/)

Thieme Medical and Scientific Publishers Pvt. Ltd., A-12, 2nd Floor, Sector 2, Noida-201301 UP, India 
neuro-interventionalists. The trans-radial arterial access (TRA) was first introduced in cardiology literature in 1989 for coronary angiography. ${ }^{2}$ Very soon TRA gained popularity among interventional cardiologists as a diagnostic and therapeutic tool because of decreased arterial puncture related complications as most of the patients undergoing coronary procedures were on anticoagulation therapy. The TRA for neurointervention procedures was first introduced in $2000 .^{3}$ However it didn't gain much popularity back then probably due to lack of familiarity with the technique, stiffer neurointervention hardware and lack of comfort among neurointerventionalists to image entire cerebral vasculature using TRA.

\section{Conventional Trans-femoral Access}

The common femoral artery has remained the preferred arterial access site for most neurointerventions. ${ }^{4}$ This may be because of larger calibre of the vessel (which gives more confidence when introducing large profile sheaths / catheters), absence of catheters specifically designed for TRA and absence of formal training in medical schools for TRA. However, TFA has some limitations. Cannulation of the aortic arch vessels using TFA might be challenging in patients with type 3 aortic arch, extensive atherosclerotic disease involving arch and descending aorta, ilio-femoral athero-occlusive disease, atypical branching patterns, coarctation or flow limiting dissections of aorta or ilio-femoral vessels. ${ }^{5,6}$ Apart from these limitations, access-site complications have been reported in $5.13 \%$ in a meta-analysis of RCTs and $2.78 \%$ in a meta-analysis comprising non-RCTs. ${ }^{7}$ Some of these complications include groin or retroperitoneal hematoma, arterial dissection, pseudoaneurysm or arterio-venous fistula formation, femoral nerve injury, lower limb ischemia, etc. ${ }^{8,9} \mathrm{~A}$ potential drawback of TFA is the requirement of leg immobilization post procedure to avoid access related complications, which in turn lengthens the hospital stay and adds on to the discomfort to the patients. Though various vascular closure devices are now available to decrease the duration of post procedure immobilization, these are expensive and are not completely free of potential complications. ${ }^{9}$

\section{Transradial Access-'Why the need?'-'Is it Worth'}

TRA is safe and effective for variety of interventional procedures. Several large-scale studies, particularly in the field of interventional cardiology, have shown that radial artery access is associated with fewer access site complications and better patient satisfaction measures than the standard TFA. Despite being used by cardiology colleagues for last two decades, TRA has only recently started to gain prominence in the field of neurointervention. ${ }^{3,4}$ However, majority of studies published in past 5 years demonstrates that TRA is safe and effective for a broad range of neuroendovascular procedures, and gives patients faster recovery with less procedural risk. $^{4-6}$ TRA is particularly useful in obese patients, patients with difficult type III aortic arch, bovine arch, significant aorto-iliac atherosclerotic disease or in cases where right vertebral artery is difficult to cannulate through TFA route. ${ }^{9}$ Though TRA requires a learning curve and commitment, it is definitely of worth, especially in patients on anticoagulation (as TRA has lower incidence of access related complications) or aorto -iliac occlusion.

\section{Why we Trailed (Behind Cardiology)?}

There is still hesitation and apprehension to use TRA for neurointerventions and majority of neuro-interventionists prefer TFA on which they are conventionally trained. Smaller caliber of the radial artery, absence of dedicated hardware for the TRA neurointerventions, absence of large patient cohort studies with long term outcomes on radial artery and lack of experience for catheter manipulation to track up to the target vessels might be the reason why neurointervention community trailed behind cardiology.

\section{Technique and Hardware/Pharmacology}

Though controversial, ${ }^{10,11}$ TRA usually starts with evaluation of the collateral circulation to the hand via Allen's and Barbeau tests. ${ }^{10}$ There are however, many reports from cardiology literature (MATRIX trial) and some from neurointerventional field, which question the need and efficacy of these tests to predict probability of hand ischemia post TRA. ${ }^{10-12}$ Although no major complications have been attributed to patients undergoing TRA with positive or equivocal Allen's test, there is some theoretical role of these tests to avoid devastating complication of hand ischemia. ${ }^{13}$ Many centres however donot routinely recommend it prior to TRA procedures. Right side TRA is most frequently chosen as it is more convenient and favorable to the operator. ${ }^{12}$ Usually the arm is kept supine and abducted with a towel roll underneath (-Fig. 1). Assessment of the diameter of radial artery $(>2.5 \mathrm{~mm})$ prior to TRA has been advised in literature, especially when introducer sheath of $>6 \mathrm{Fr}$ is to be used ${ }^{14}$ to avoid radial artery dissection or occlusion. ${ }^{15}$ Use of topical lidocaine and nitroglycerin or subcutaneous nitroglycerin at least 30 minute prior to puncture might help to increase the

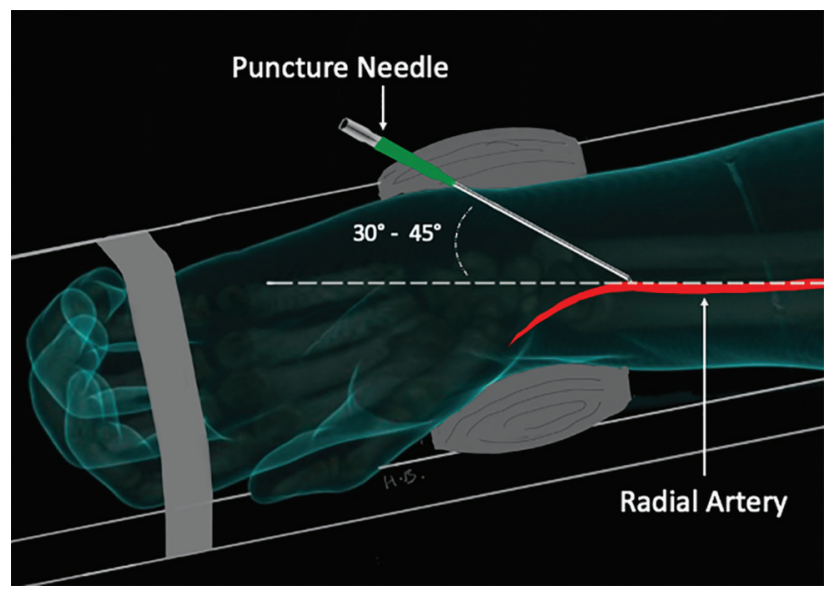

Fig. 1 Diagrammatic representation of the positioning of the wrist and needle insertion path during transradial puncture. 
diameter of the radial artery and facilitate TRA. ${ }^{16}$ Surface heating with Balbay maneuver has been reported to reduce radial artery spasm. It is defined as heating the radial artery site for three minutes with the palm following administration of lignocaine for local anesthesia subcutaneously. ${ }^{17}$

Traditionally, TRA is obtained $\sim 2-3 \mathrm{~cm}$ proximal to the palmar wrist crease. More distal TRA in the anatomical snuffbox (-Fig. 2) has some advantages like reducing the need of keeping the wrist supine and also allowing for re-access at the more proximal site. ${ }^{18}$ Micro-puncture radial access set (21gauge needle, 0.018" micro-guidewire, and sheath (either 4, 5 , or $6 \mathrm{~F}$ ) is preferred. Radial sheath size may depend upon the radial artery diameter and endothelial injury to radial artery increases with increasing sheath diameter. ${ }^{18,19}$ Most neurovascular procedures require $6 \mathrm{~F}$ sheath for navigation of the hardware. Several radial access sheaths are currently available in the market. As compared with femoral sheaths, they have a better hydrophilic coating, tapered dilator snugly fitting the sheath and thinner outer wall so that the outer diameter is lesser than the actual size while at the same time preserving the inner diameter. Some of these are Radifocus Introducer Transradial Kit (Terumo), Prelude Radial Sheath Introducer (Merit), Radial Access Sheath Kits (Arrow), Glidesheath Slender Introducer Sheath (Terumo) and Rain Sheath (Cordis). To prevent radial artery spasm or thrombosis, use of unfractionated heparin at therapeutic levels ( $50-70 \mathrm{U} / \mathrm{kg}$ or $5000 \mathrm{U}$ ) and intra-arterial antispasmodic medications (nitroglycerin $200 \mu \mathrm{g}$ and verapamil $5 \mathrm{mg}$ ) is recommended. ${ }^{19,20}$ The most common successfully employed radial cocktails are

1. Combination of heparin (2,500 units), nitroglycerin $(0.2 \mathrm{mg})$ and verapamil $(2.5 \mathrm{mg})$ diluting it with $0.9 \%$ sodium chloride to obtain $10 \mathrm{ml}$ solution.

2. Combination of heparin (2,500 units), nitroglycerin $(0.2 \mathrm{mg})$ and diltiazem (2.5 mg) diluting it with $0.9 \%$ sodium chloride to obtain $10 \mathrm{ml}$ solution.

Few physicians have also used a single vasodilator $(0.2 \mathrm{mg}$ nitroglycerin) with reasonable results. Some physicians have used equivalent dose of nicardipine $(1 \mathrm{mg})$ or nimodipine

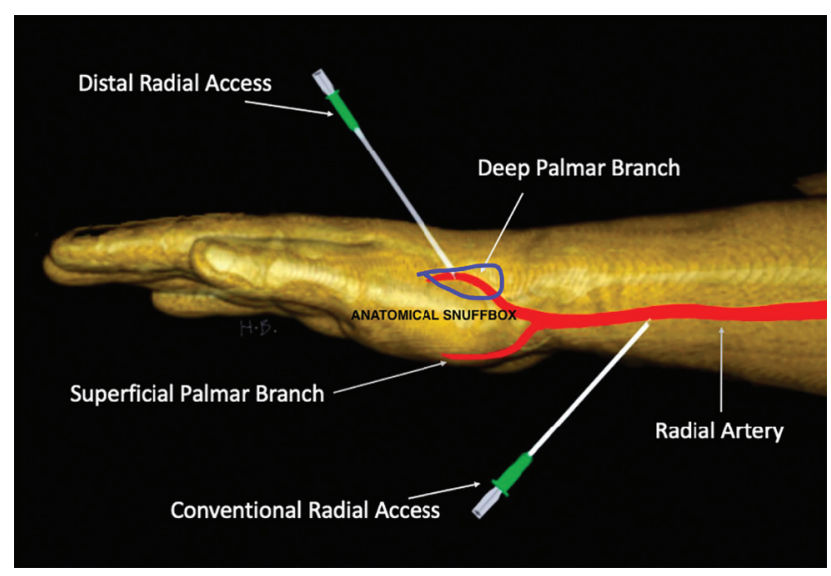

Fig. 2 Diagrammatic representation of the needle insertion targets in the conventional and distal radial access during transradial puncture. Note that the distal radial access is downstream in the 'anatomical snuffbox' beyond the origin of the superficial palmar branch.
( $2 \mathrm{mg}$ ) alongwith nitroglycerin as the second agent for spasm prevention. The latter (nimodipine) is being tested by the authors in their institute due to its easy availability in neurovascular practice. Another recommendation is to aspirate some quantity of blood in the cocktail syringe before injecting the entire mixture into the radial artery. This has been associated with reduced pain. If frequent catheter changes are encountered during the procedure the radial cocktail can also be repeated to reduce the chances of radial spasm ( - Fig. 3). Use of anxiolytics before the procedure also decrease the chance of vascular spasm. Some studies have described direct placement of larger guide catheters without radial sheaths for neurointervention as a means of reducing spasm. $^{21}$

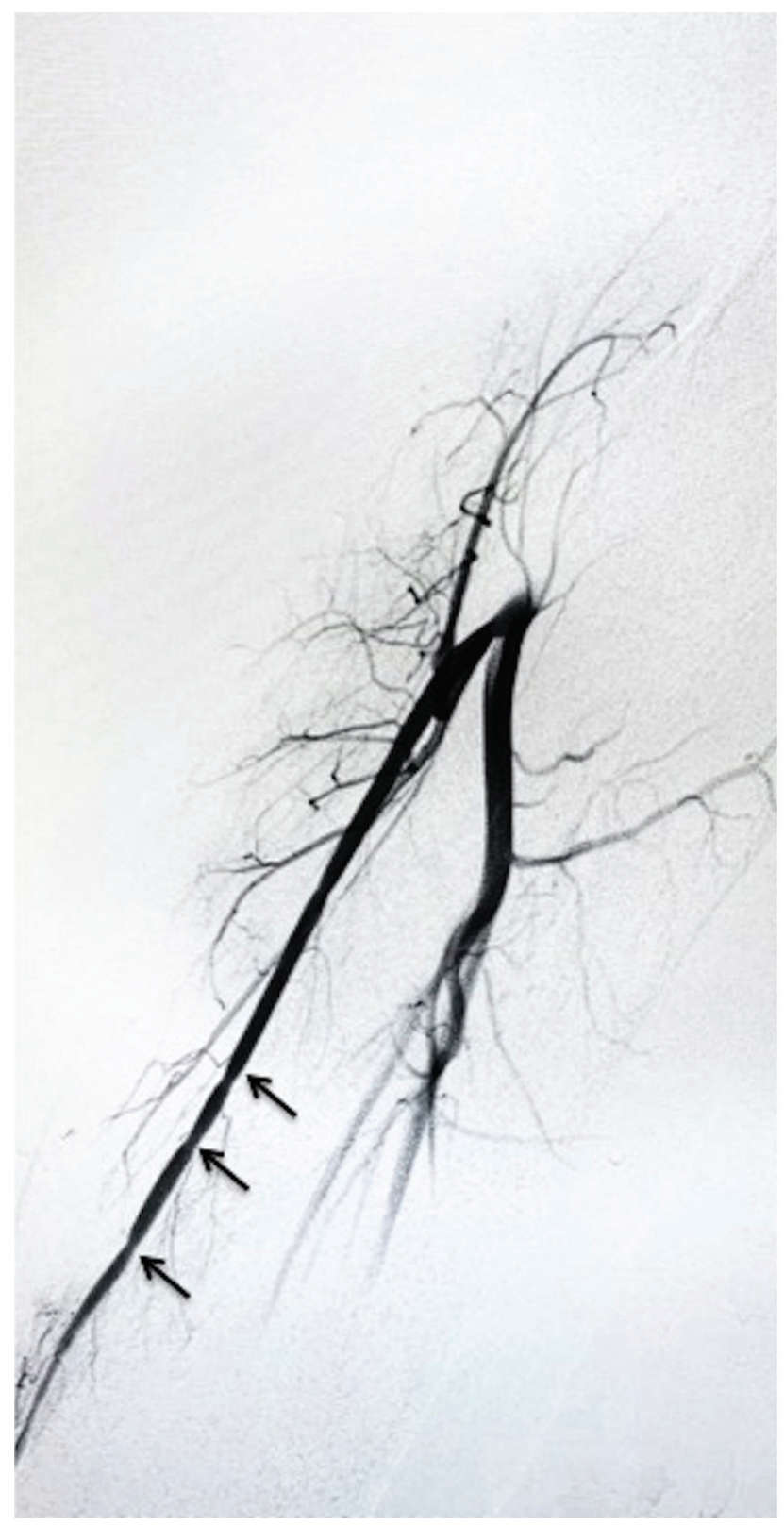

Fig. 3 Radial artery angiogram following sheath insertion shows vasospasm due to wire manipulation. This can be easily relieved with a small dose of spasmolytic. 
Simmons 2 is the best catheter that serves to hook the arteries of the aortic arch. The curve of the Simmons is usually formed in the descending aorta. Other sites where the curve can be created is against the aortic arch or one of the arteries along the way of the catheter from the radial artery namely the right vertebral artery or the right common carotid artery. There has been development of some indigenous catheters specifically designed for neurovascular procedures to mitigate the natural curves of the artery origins and to make up for the long route to the left internal carotid artery. ${ }^{22,23}$ Medtronic has designed a guiding catheter specifically for radial use (RIST ${ }^{\mathrm{TM}}$ ) having radial-specific transition zones. Other guiding catheters that have worked well are Ballast (Balt) and Benchmark (Penumbra). Unfortunately, balloon guide catheter cannot be introduced through the trans-radial route, which markedly improves outcomes in stroke thrombectomy.

For TRA site closure, an external pneumatic radial compression band with patent hemostasis technique and simultaneous ulnar artery compression is recommended over manual compression as the former technique reduces rate of arterial occlusion. ${ }^{15}$ Pneumatic compression cuff (TR band) is much simpler and easier to use as well as cheaper than devices used for femoral arteriotomy closure.

\section{Potential Adverse Effects}

Though TRA is considered safer than TFA, potential complications associated with the former technique are radial artery stenosis and occlusion. The incidence of radial artery stenosis ranges from 6\%-30\% (reduced rates of stenosis are noted after intraarterial administration of spasmolytics). ${ }^{24}$ Some of the maneuvers like repeating intraarterial spasmolytics, warm compressions, sedating the patient or general anesthesia might help reduce the radial artery spasm. ${ }^{15,24}$ Radial artery occlusion is rare and can be managed by administration of heparin or maneuvers like ulnar compression to promote recanalisation. ${ }^{25}$ In our experience in majority of the patients even occlusion of the radial artery remains asymptomatic.

Other rare complications that have been reported in literature are pseudoaneurysms, hematomas, dissections, thromboembolic phenomena due to manipulation of Simmon's catheter in the arch, etc. ${ }^{24}$ Sometimes the presence of anatomical variants like radial loop and aberrant right subclavian artery (-Fig. 4 ) makes the negotiation of the diagnostic catheters and wires difficult resulting in prolongation of the procedure. However, with the cardiology and now growing neurointervention experience, these conditions can be confidently tackled with fluoroscopy/roadmap guidance guidewire manipulation or by using microcatheters to cross and straighten the loops. Preprocedure assessment of the cervicocranial CT angiography may be helpful in identifying vascular anomalies like aberrant subclavian artery and planning accordingly.

Another limitation associated with TRA is the potential wear and tear of the accessed radial artery, especially if chosen multiple times for neurointerventional procedures.

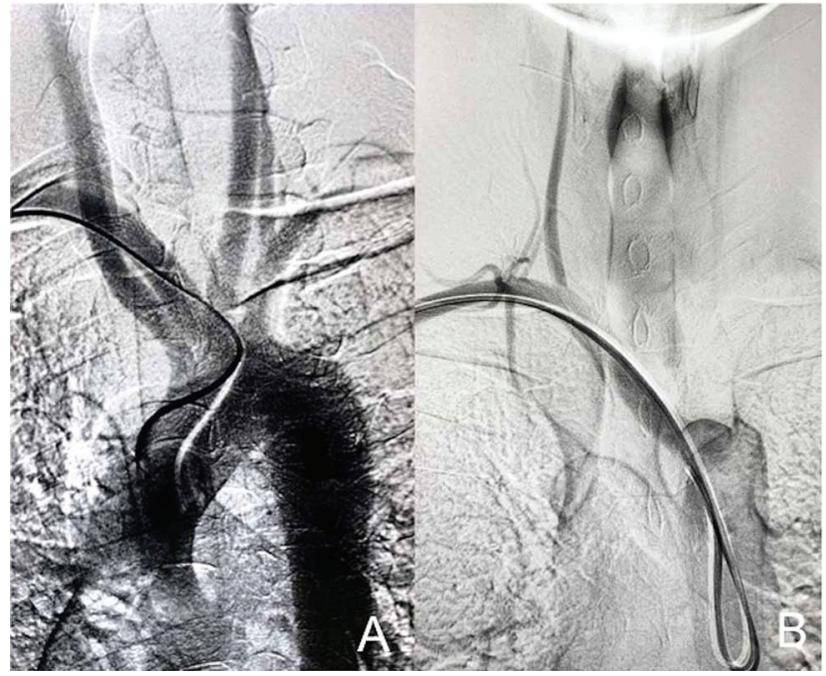

Fig. 4 Arch aortogram (A) demonstrating separate origins of right common carotid, right subclavian, left common carotid and left subclavian arteries from the aortic arch with the right subclavian artery having aberrant origin from the dorsal surface of the arch (B) just distal to the left subclavian artery origin.

This may make it non-usable as a bypass graft, if at all required, any time in future in cases of coronary artery disease.

\section{Current Evidence}

For the purposes of diagnostic cerebral angiography, the success rate of TRA has been reported in literature between $88 \%$ and $99 \%$ depending upon the experience of the operator. ${ }^{9,26}$ When compared with TFA, TRA has lower incidence of major access related complications. ${ }^{27,28}$ Since radial artery is a superficial vessel with narrow caliber, it is easily compressible after TRA with reduced risk of access related complications. TRA is particularly useful in obese patients, patients with difficult type III aortic arch, bovine arch, significant aorto-iliac atherosclerotic disease or in cases where right vertebral artery is difficult to cannulate through TFA route. Some case reports have described the superiority of TRA over TFA in providing stability to guide catheters during therapeutic neuro-interventions as small diameter of radial artery provides enough support. ${ }^{29,30}$ TRA is also preferred over TFA in patients on anti platelets/anticoagulation with lower incidence of puncture site complications ${ }^{31}$ and in pregnant patients, where abdomen can be covered with lead shield to decrease foetal exposure. ${ }^{32}$ Following TFA, patients are expected to immobilize the groin/ leg used for access for at least 4-6hours which might be uncomfortable for elderly, obese patients or patients with backache. It might lead to bowel/ bladder related problems and further increase in backache and discomfort. Though closure devices can be used after TFA, these are costly with added risk of complications. Cooper et $\mathrm{al}^{33}$ and Kok et $\mathrm{al}^{34}$ showed that TRA was preferred over TFA by majority of patients who had to undergo both transradial and transfemoral approaches for cardiac catheterisation due to decreased body pain, back pain and early ambulation during first day of procedure. Similar 
results were showed by Satti et $\mathrm{al}^{35}$ in patients who underwent neuro-endovascular procedures using TRA. Though there are some case reports showing longer procedure times with TRA, there are others which did not find any significant difference between TRA and TFA. ${ }^{31,32}$ Another advantage of TRA is reduced duration of post procedure hospital stay and thus procedure cost for both cardiac or neuro-intervention procedures. $^{33,34}$

Given all the advantages, TRA has its share of some limitations too. The technique requires a learning curve, with a neurointerventionalist needing to perform at least 50 to 100 consecutive cases to gain certain experience to feel comfortable with this approach. ${ }^{32}$ In general, this learning curve is steeper than of learning transfemoral access. There are high conversion rates from TRA to TFA, especially for the beginners, due to radial artery stenosis, anatomical variants like radial loops, artery lusoria etc and difficult cannulation of left CCA or left vertebral artery. ${ }^{9}$ Left sided TRA can be helpful in such cases. Another disadvantage is inability to use large profile sheaths/catheters, especially in elderly and female patients. ${ }^{35}$

\section{So! Are we Ready for the Transit?}

Though TRA seems attractive in terms of patient comfort, reduced hospital stay, lesser procedure costs and lower risk of complications, unfortunately, all transradial interventions are done using catheters originally dedicated to the TFA, which in turn leads to higher rates of conversion to TFA. Before using TRA as the first choice for all the neurointervention procedures, we need dedicated low profile sheaths and catheters that could track up to the target vessel, especially for left CCA and vertebral artery. The technique requires a learning curve and institutional commitment and investment in teaching the technique to neurointervention fellows and residents, establishing new protocols, and finding best practices. It is recommended to start TRA for diagnostic cerebral angiographies (at least 50 to 100), followed by elective neurointervention cases and finally emergency cases like mechanical thrombectomies. After certain experience with this approach, nearly all neurointervention patients should be considered candidates for TRA. It is recommended to study arch and subclavian vessels whenever CT angiogram is available to ensure that there is no anatomic contraindication for TRA. Left sided TRA or even trans ulnar approach can be used in certain cases.

\section{Will Trans-femoral still have a Place in the Access Armamentarium?}

With all the advantages and disadvantages of TRA mentioned above, we believe that though TRA is the future, TFA would still have a place in the access armamentarium, especially in children, elderly patients with small radial arteries and patients with anatomical variants. There is definitely a need of dedicated neuroendovascular hardware specially designed for safe transradial approach to neurointerventions. As far as tortuosity of subclavian vessels or vertebral vessels is considered, use of left side TRA might be considered before converting to TFA. TFA might be preferred over TRA in patients of certain professions like musicians and artists who are concerned about possible complications of TRA approach.

\section{Conclusion}

TRA has several advantages over TFA and can be considered as an effective and safe approach for performing various diagnostic and therapeutic neuro endovascular procedures. TFA is clearly associated with patient satisfaction in terms of reduced hospital stay and early ambulation. Continuous utilization of TRA would help build operator experience and comfort, which might help to replace TFA in near future for most of the neurointerventional procedures.

Financial Support

Nil.

Financial Disclosure

Nil.

Conflict of Interest

None declared.

Acknowledgments

The authors wish to acknowledge the contribution of $\mathrm{Dr}$ Harish Bhujade in designing the - Figs. 1 and $\mathbf{2}$.

\section{References}

1 Artico M, Spoletini M, Fumagalli L, et al. Egas Moniz: 90 Years (1927-2017) from Cerebral Angiography. Front Neuroanat 2017; 11:81

2 Campeau L. Percutaneous radial artery approach for coronary angiography. Cathet Cardiovasc Diagn 1989;16(01):3-7

3 Matsumoto Y, Hokama M, Nagashima H, et al. Transradial approach for selective cerebral angiography: technical note. Neurol Res 2000;22(06):605-608

4 Haussen DC, Nogueira RG, DeSousa KG, et al. Transradial access in acute ischemic stroke intervention. J Neurointerv Surg 2016;8 (03):247-250

5 Jo KW, Park SM, Kim SD, Kim SR, Baik MW, Kim YW. Is transradial cerebral angiography feasible and safe? A single center's experience. J Korean Neurosurg Soc 2010;47(05):332-337

6 Fessler RD, Wakhloo AK, Lanzino G, Guterman LR, Hopkins LN. Transradial approach for vertebral artery stenting: technical case report. Neurosurgery 2000;46(06):1524-1527, discussion 15271528

7 Oneissi M, Sweid A, Tjoumakaris S, et al. Access-Site Complications in Transfemoral Neuroendovascular Procedures: A Systematic Review of Incidence Rates and Management Strategies. Oper Neurosurg (Hagerstown 2020;19(04):353-363

8 Lee DH, Ahn JH, Jeong SS, Eo KS, Park MS. Routine transradial access for conventional cerebral angiography: a single operator's experience of its feasibility and safety. Br J Radiol 2004;77(922): 831-838

9 Levy EI, Boulos AS, Fessler RD, et al. Transradial cerebral angiography: an alternative route. Neurosurgery 2002;51(02):335-340, discussion 340-342

10 Valgimigli M, Campo G, Penzo C, Tebaldi M, Biscaglia S, Ferrari RRADAR Investigators. Transradial coronary catheterization and 
intervention across the whole spectrum of Allen test results. J Am Coll Cardiol 2014;63(18):1833-1841

11 Bertrand OF, Carey PC, Gilchrist IC. Allen or no Allen: that is the question!. J Am Coll Cardiol 2014;63(18):1842-1844

12 Valgimigli M, Frigoli E, Leonardi S, et al. MATRIX Investigators. Radial versus femoral access and bivalirudin versus unfractionated heparin in invasively managed patients with acute coronary syndrome (MATRIX): final 1-year results of a multicentre, randomised controlled trial. Lancet 2018;392(10150):835-848

13 Starke RM, Snelling B, Al-Mufti FSociety of NeuroInterventional Surgery. et al. Transarterial and transvenous access for neurointerventional surgery: report of the SNIS Standards and Guidelines Committee. J Neurointerv Surg 2020;12(08):733-741. Doi: 10.1136/neurintsurg-2019-015573

14 Kherad B, Köhncke C, Spillmann F, et al. Postprocedural radial artery occlusion rate using a sheathless guiding catheter for left ventricular endomyocardial biopsy performed by transradial approach. BMC Cardiovasc Disord 2016;16(01):253-53

15 Rashid M, Kwok CS, Pancholy S, et al. Radial artery occlusion after transradial interventions: a systematic review and meta-analysis. J Am Heart Assoc 2016;5(01):e002686

16 Beyer AT, Ng R, Singh A, et al. Topical nitroglycerin and lidocaine to dilate the radial artery prior to transradial cardiac catheterization: a randomized, placebo-controlled, double-blind clinical trial: the PRE-DILATE Study. Int J Cardiol 2013;168(03): 2575-2578

17 Ünal S, Açar B, Yayla Ç, et al. Manual heating of the radial artery (Balbay maneuver) to facilitate radial puncture prior to transradial coronary catheterization. Rev Port Cardiol 2017;36(06): 409-414

18 McCarthy DJ, Chen SH, Brunet M-C, Shah S, Peterson E, Starke RM. Distal radial artery access in the anatomical snuffbox for neurointerventions: case report. World Neurosurg 2019;122:355-359

19 Dahal K, Sharma S, Yousuf A, et al. A comparison of standard versus low dose heparin on access-related complications after coronary angiography through radial access: A meta-analysis of randomized controlled trials. Cardiovasc Revasc Med 2018;19(5 Pt B):575-579

20 Kiemeneij F, Vajifdar BU, Eccleshall SC. Laarman G, Slagboom T, van der Wieken R. Evaluation of a spasmolytic cocktail to prevent radial artery spasm during coronary procedures. Catheter Cardiovasc Interv 2003;58(03):281-284

21 Horie K, Tada N, Isawa T, et al. A randomised comparison of incidence of radial artery occlusion and symptomatic radial artery spasm associated with elective transradial coronary intervention using 6.5 Fr SheathLess Eaucath Guiding Catheter vs. 6.0 Fr Glidesheath Slender. EuroIntervention 2018;13(17):2018-2025
22 Luo N, Qi W, Tong W, et al. Efficacy and Safety of a Novel Catheter for Transradial Cerebral Angiography. Ann Vasc Surg 2019; 60:236-245

23 Balaban Y. Effectiveness of a handmade "New Carotid Catheter" in transradial carotid angiography: A comparison with conventional multipurpose catheters. J Interv Cardiol 2018;31(01):94-105

24 Caputo RP, Tremmel JA, Rao S, et al. Transradial arterial access for coronary and peripheral procedures: executive summary by the Transradial Committee of the SCAI. Catheter Cardiovasc Interv 2011;78(06):823-839

25 Bernat I, Bertrand OF, Rokyta R, et al. Efficacy and safety of transient ulnar artery compression to recanalize acute radial artery occlusion after transradial catheterization. Am J Cardiol 2011;107(11):1698-1701

26 Hildick-Smith DJ, Walsh JT, Lowe MD, Shapiro LM, Petch MC. Transradial coronary angiography in patients with contraindications to the femoral approach: an analysis of 500 cases. Catheter Cardiovasc Interv 2004;61(01):60-66

27 Louvard Y, Lefèvre T, Allain A, Morice M. Coronary angiography through the radial or the femoral approach: The CARAFE study. Catheter Cardiovasc Interv 2001;52(02):181-187

28 Brener MI, Bush A, Miller JM, Hasan RK. Influence of radial versus femoral access site on coronary angiography and intervention outcomes: A systematic review and meta-analysis. Catheter Cardiovasc Interv 2017;90(07):1093-1104

29 Layton KF, Kallmes DF, Cloft HJ. The radial artery access site for interventional neuroradiology procedures. AJNR Am J Neuroradiol 2006;27(05):1151-1154

30 Nohara AM, Kallmes DF. Transradial cerebral angiography: technique and outcomes. AJNR Am J Neuroradiol 2003;24(06): 1247-1250

31 Lee DG, Lee DH, Shim JH, Suh DC. Feasibility of the transradial or the transbrachial approach in various neurointerventional procedures. Neurointervention 2015;10(02):74-81

32 Snelling BM, Sur S, Shah SS, et al. Transradial cerebral angiography: techniques and outcomes. J Neurointerv Surg 2018;10(09): 874-881

33 Cooper CJ, El-Shiekh RA, Cohen DJ, et al. Effect of transradial access on quality of life and cost of cardiac catheterization: A randomized comparison. Am Heart J 1999;138(3 Pt 1):430-436

34 Kok MM, Weernink MG, von Birgelen C, Fens A, van der Heijden LC, van Til JA. Patient preference for radial versus femoral vascular access for elective coronary procedures: The PREVAS study. Catheter Cardiovasc Interv 2018;91(01):17-24

35 Satti SR, Vance AZ, Golwala SN, Eden T. Patient preference for transradial access over transfemoral access for cerebrovascular procedures. J Vasc Interv Neurol 2017;9(04):1-5 